\title{
Dystonia Pathophysiology: A Critical Review
}

\author{
Pierre Burbaud \\ Department of Clinical Neurophysiology, Centre Hospitalier de Bordeaux, \\ Institut des Maladies Neurodégénératives (CNRS UMR5293), \\ Université Victor Segalen, Bordeaux,
}

France

\section{Introduction}

During the past years, dramatic progress have been achieved in our knowledge of the pathophysiology of dystonia on the basis of imaging and electrophysiological data collected in human patients. Converging arguments now support the role of combined corticostriatal and cerebellar dysfunctions in the genesis of this movement disorder (1). Several excellent reviews have been recently proposed on this topic (2-8). Moreover, animals models of dystonia can help us to investigate the pathogenesis since they provide the opportunity to dissect more precisely the abnormal neuronal networks leading to primary dystonia and its genetic background (9-12).

However, many points remain to be clarified. Here, we discuss some of the findings previously reviewed but will detail more specifically less recognized aspects of the pathophysiology of dystonia, such as the link between phenomenology and physiology and the lessons that we can get from animal models.

\section{Phenomenological considerations}

Dystonia is defined as a syndrom of sustained muscular contractions leading to repetitive movements and abnormal postures. However, a rapid overview of the litterature reveals that this term is broadly used in very different contexts and can be associated with various pathological conditions. Thus, there is a need for clarification, not only for highlightening the concept of dystonia, but above all because of the pathophysiological and therapeutical consequences. In dystonia, abnormal posture is linked to repetitive muscular spasms triggered or worsened by voluntary movement (13). The overspreading of muscular activity to muscles usually not involved in the movement corresponds to a loss of inhibition during movement execution $(3,14)$. However, dystonia can be observed in different conditions such as spasticity, primary dystonia, secondary dystonia, levodopa-induced dystonia and offdystonia in parkinsonian patients, among others.

Initially, several types of dystonia have been proposed depending on the age of onset, topography of clinical signs, and primary or secondary origin of dystonia (13). Focal dystonia is the most frequent form with a categorization depending on localization in the facial musculature (blepharospasm, oromandibular dystonia), cervical region (spasmodic 
torticolis), limb (occupational dystonia e.g. writer'scramp or musician's cramp) or the larynx (laryngeal dystonia). Segmental dystonia involves two or more contiguous regions e.g. the cervical region and one limb, and corresponds to the diffusion of the dystonic process to close anatomic regions. This point suggests a spreading of abnormal motor command in a somatotopic manner. Although multifocal dystonia encompasses non-adjacent body part, it is less frequent in clinical practice. Hemidystonia is limited to one hemibody and frequently associated with lesions of the controlateral hemisphere. However, as for most of secondary dystonia, it is characterized by permanent tonic postures very different from the clinical pattern seen in primary dystonia. General dystonia have a broader distribution than focal dystonia but also frequently encompasses adjacent parts of the body e.g lower limb and trunks and/or upper limbs. Dystonia is primary when no lesions of the central nervous system or metabolic abnormalities are found (15) whereas it is associated with other neurological troubles in dystonia-plus syndroms (2). In secondary dystonia, lesions generally concern the basal ganglia and more particularly the putamen although lesions in other regions have been reported (16).

It is critical to be precise as to which type of dystonia we are dealing with. The fixed focal dystonia frequently observed in untreated Parkinson's disease (off-dystonia) or in various neurological disorders encompassing dystonia and parkinsonism is likely to correspond to a form of focal akineto-rigid syndrome There are clinical and experimental arguments supporting this view. For instance, off-dystonia in Parkinsonian patients is observed in a state of low dopaminergic plasma levels either before treatment (off-state) or as a end-ofdose effect. A fixed focal dystonia, generally in the lower limb, is frequently noticed in MPTP-treated monkey at the onset of intoxication and before the development of a full akinetic-rigid syndrome in a situation where dopaminergic neurons are only partially destroyed (17). In dopa-sensitive dystonia (DRD), tonic postures are frequently encountered, sometimes in association with a parkinsonian syndrome ; the use of dopaminergic treatment is effective because there is a decrease in the production and consequently the availability of dopamine at the nigro-striatal synapsis. In secondary dystonia where most of the lesions involve the putamen, a fixed dystonia with a somatotopic organisation is most frequently observed. In this case, lesions seriously disrupt the organisation of motor patterns at the striatal level, the support of procedural memory. This point explains the inability of patients to control accurately the spatio-temporal pattern of agonist and antagonist muscles necessary to achieve a smooth and goal-directed movement.

Primary dystonia is clearly an hyperkinetic movement provoked or accentuated by voluntary movement. Fixed posture at rest are observed only in the most evoluated forms of the disease such as long-lasting DYT1 dystonia or spasmodic torticollis. A critical feature of mobile dystonia is that each patient exhibits his own abnormal motor pattern, repetitive in time and space. For instance, a patient with cervical dystonia will have a specific pattern of neck posture, a patient with generalized dystonia the same kind of back-arching movements and lower limb movements. Similar remarks could be made for levodopa-induced dyskinesia (LID) and/or dystonia: each patient exhibits his own pattern of LID. In addition, we must point out the fact that by many aspects, LID are more dystonic in nature than choreic: they frequently associate repetitive myoclonic jerks and mobile abnormal postures but are rarely eratic as the choreic movements observed in Huntington's disease. One interpretation of the phenomenon could be that in primary dystonia the disorganization of networks controlling movement occurs in patch within the striatum $(18,19)$. 


\section{Lessons form primate models of dystonia: The physiological approach}

Primate models of dystonia are informative, first because of the tight phylogenetic link between monkeys and humans, but also because they provide the possibility to obtain phenotypes of dystonia in the monkey using a more invasive physiological approach than in humans.

It was found initially that brain regions involved in the regulation of muscular tone, such as the red nucleus or dorsomedial mesencephalic tegmentum, provoked the appearance of a spasmodic torticollis (20). The head was turning to the side of the tegmental lesion. Moreover, electrical stimulations or pharmacological inactivation of the interstitial nucleus of Cajal (NIC) induced neck dystonia, a result which can be explained by the role of NIC in the control of head posture (21). The cervical dystonia observed in this condition is characterized by lateral flexion of the head to the shoulder opposite to the site of the lesion and intermittent co-contraction of neck muscles resulting in spasmodic head movements. Muscimol (22) or histamine (23) injections within the red nucleus also induced a cervical dystonia as well as pharmacological manipulations of vestibular nucleii (24).

In monkeys, as in humans, systematic treatments acting on the dopaminergic system induce dystonia. These models could provide some lights on two aspects of the pathophysiology of primary dystonia : 1) the putative role of dopaminergic receptors, 2) the implication of the direct and indirect striato-pallidal pathways. Acute dystonia was first reported in the primate after haloperidol injections (25) with a response to anti-cholinergic drugs $(26,27)$ and reserpine (28). On the other hand, clozapine (a second generation antipsychotic agent) compared to classical neuroleptics (first generation antipsychotic agents) did not provoke acute dystonia possibly due to its particular post-synaptic receptor affinity to D1 receptors (29). Conversely, injections of D1 agonists induced less frequently acute dystonia than D2 receptor antagonists $(30,31)$. Thus, it seems that acute dystonia, frequently hypertonic in its clinical expression, is mainly trigerred by the blockade of D2 receptors. Tardive dystonia can be induced by a chronic treatment with neuroleptics (32-35). As for acute dystonia, drugs that prevent dopamine storage (reserpine), synthesis ( $\alpha$-methyl-p-tyrosine) or block dopamine receptors decrease tardive dyskinesias (36). However, there is some pharmacologic evidences for a peculiar implication of D1 dopaminergic receptors in orofacial dystonia (37). The substitution of a D2 antagonist by a D1 antagonist decreases the clinical expression of dystonia (38). Thus, in tardive dystonia which is frequently mobile, the overactivity of the direct pathways could play a preponderant role.

When Bicuculline (Bic), a potent antagonist of $\mathrm{GABA}_{\mathrm{A}}$ receptors, is injected directly within the GPi or $\mathrm{SNr}$, it induces at high volumes $(10 \mu \mathrm{l})$ a severe parkinsonian syndrome similar to that observed in MPTP-treated monkeys. However, when lower volumes $(2 \mu \mathrm{l})$ are used, abnormal focal postures in the lower limbs close to off-dystonia are observed (39). Severe hypertonic postures in controlateral limbs are noticed after GPi injections whereas $\mathrm{SNr}$ injections generally induce more axial symptoms, particularly in the neck. Thus, this type of dystonia characterized by hypertonia and bradykinesia corresponds to a form of focal akinetic-rigid syndrome, the somatotopy of which depending on the targeted basal ganglia. In MPTP monkeys, chronic treatment with levodopa or apomorphine induces dyskinesia (40-42). Metabolic studies relying on 2-Desoxyglucose (2-DG) show an increase of GABAergic inhibition of the subthalamic nucleus, suggesting a diminished subthalamo- 
pallidal activity (40-42). This data would suggest an increased activity within the thalamocortical network although thalamotomy did not improve dystonia in MPTP-treated monkeys $(43,44)$. During peak-dose dystonia, an increase in the expression of D1 dopaminergic receptors was observed and interpreted as an overactivity of the direct striato-pallidal pathway. On the other hand, D1 agonists induce less dyskinesias than D2 agonists $(45,46)$.

Bic injection into the STN blocks GABAergic inputs, increases activity and leads to a tonic dystonia (42). Conversely, the injection of muscimol, a GABAergic agonist, within the basal ganglia output structures, namely the internal pallidum (GPi), and pars reticulata of the substantia nigra ( $\mathrm{SNr}$ ) induces a mobile dyskinesias encompassing mixed choreic and dystonic features mimicking the hyperkinetic movements observed in idiopathic dystonias (39). The mechanism could be related to an inhibition of neuronal activity in these regions (47).

A line of evidence also suggest that manipulations of the striatum might induce dystonia. Bicuculline injections within the putamen in the cat provoked neck dystonic movements directed towards the controlateral side, associated with an increased activity within the striatum and concomitent inhibition in the substantia nigra pars reticulata (SNr) (48). Injection of the same drug within the putamen also induced contralateral dyskinesia in the monkey (49). The blockade of striatal GABA $\mathrm{A}_{\mathrm{A}}$-receptors in the striatum increases GPI neuronal activity and induces EEG spikes in the primary motor cortex (50). Direct electric stimulation of the putamen in the monkey using various duration of stimulation trains induces movement disorders the nature of which depending on the duration of the stimulation train (51). With short duration (100ms), myoclonic jerks of the contralateral hemibody are observed whereas dystonic and stereotyped movements are noticed with longer duration trains $(>500 \mathrm{~ms})$. These data suggest that the difference between myoclonus and dystonia relies on the duration of the abnormal neuronal activity generated within the putamen.

An increased activity in the direct striato-pallidal pathway is likely to induce changes in the motor thalamus. Lesion studies in humans indicate that dystonia is mainly observed after lesions of the caudal motor thalamus (Vc, VIM) but not of the rostral pallidal segment (Vop) $(52,53)$. In monkey, the motor thalamus is a complex structure encompassing several regions (54). Its rostral part, corresponding to the ventrolateral pars oralis (VLo) and ventral anterior (VA) nucleii, receives inputs from basal ganglia output structures and send projections to the supplementary motor area (55). The caudal part corresponding to the ventroposterolateral, pars oralis (VPLo) and ventrolateral, pars caudalis (VLc) nucleii mainly receive cerebellar inputs. The projections are directed to the primary motor cortex (54). Several lines of evidence suggest that the thalamus plays a role in the synchronization of cortical activity in time and space (56). Thus, its dysfunction could potentially inducea loss of selectivity in the implementation of cortical modules during motor planning. Injection of bicuculline within the rostral part (VLo and VA) provoked a mobile contralateral dystonia whereas a myoclonic dystonia was observed after injections into the caudal region (VPLo, VLc) $(57,58)$. These bicuculline injections increased the discharge frequency of thalamic neurons and decreased the threshold of current necessary to evoke motor responses after intrathalamic microstimulation (58). Moreover, a bursty pattern correlating with myoclonic jerks was observed for most neurons in the caudal region. These results suggest that the tonic and myoclonic components frequently associated in dystonic patients could be the result of a dysfunction in both the rostral (pallidal) and caudal 
(cerebellar) parts of the motor thalamus. These notions are also in congruity with the view that an hyperexcitability of thalamo-cortical pathway induces dystonia as proposed by Berardelli et al. (59). Interestingly, a greater number of thalamic neurons responded to passive joint manipulations after bicuculline injection (58). The data obtained in an acute experimental situation reveal the drastic and immediate modifications of somesthesic receptive fields that thalamic neurons may exhibit, highlighting the role of the motor thalamus in sensori-motor processing.

Taken as a whole, the results of pharmacological studies in monkeys suggest that in primary dystonia there would be an overactivity in the direct striato-palidal pathway, potentially associated with a decreased activity in the indirect striato-palidal pathway leading to a disrupted activation of the thalamo-cortical projections.

So far, the only phenotypic model of primary dystonia in the primate was that obtained in monkeys trained to perform repetitive movements (60-62). The animals performed the same movement of grasping 2 hours a day 5 days a week for 12 to 25 weeks and experienced difficulties removing their hands from the handpiece after 5-8 weeks of training, associated with a reduction in the number of trials correctly performed (60). The animals also exhibited difficulties in hand motor control during feeding, a loss of digital dexterity, evoking dystonia. In parallel, a disorganization of hand somatotopy was observed in area $3 \mathrm{~b}$ of the primary somaesthetic cortex (S1). Receptive fields of recorded neurons became larger, encompassing more than one digit and segregation between glabrous and hairy skin was altered. Moreover, it was found that hand-face border in S1 normally sharp became patchy and spread over $1 \mathrm{~mm}$ of cortex (60). Thus focal dystonia induced by repetitive behaviors generates aberrant sensory representations which interfere with motor control (63). Abnormal motor control strengthens sensory abnormalities and the positive feed-back loop reinforces the dystonic condition.

\section{Lessons from rodent models of dystonia: The genetic approach}

Models of dystonia in the rodent provide valuable tools for exploring the contribution of genetic factors in the pathophysiology of dystonia. They can be divided into those that mimic the dystonic phenotype and those that duplicate the genetic abnormalities (2). In genotypic models, the mutations that produce dystonia in humans have been introduced into mice. Several models have been developed (11). Mouse models of DYT1 include both transgenic mice expressing human mutant torsin A (hMT) $(64,65)$, and heterozygous knockin mice in which the GAG mutation has been introduced in the mouse torsin A gene (Dyt1) $(66,67)$. These mice do not have obvious dystonic features $(65,66)$ but exhibit some learning motor deficit (64). In striatal explant slices from transgenic hMT mice, cholinergic interneurons manifest an abnormal physiology: they respond to dopamine receptor (D2) activation with an increase in spiking, rather than an inhibition as observed in normal mice (68). Genotypic mouse models have also been generated for DYT5, DYT11 and DYT12 (2).

The role of dopaminergic dysfunction in dystonia is supported by several studies in the rodent (1). In a transgenic model of dopa-responsive dystonia, a depletion of tyrosine hydroxylase was found in the striatum (69). There was a marked posterior to anterior gradient with a predominant loss of striosome tyrosine hydroxylase expression in the remaining tyrosine hydroxylase staining areas at an early stage of the postnatal 
development. A DYT1 mouse model had a decreased amphetamine-induced dopamine release and evidence for an increased dopamine turnover was found (70).

In phenotypic models, mutations that produce dystonic movements occur naturally (12). The $\mathrm{dt} / \mathrm{dt}$ rat has an autosomal, recessive condition with dystonic posturing appearing 10 days after birth encompassing twisting movements of the neck, padding motions of the limbs and postural instability of increasing severity (71). Purkinje cell soma are smaller (10) and the defective protein, caytaxin, is a lipophilic binding protein that is expressed at high levels in cerebellar neurons during development $(11,72)$. This protein might be involved in signalling pathways that use calcium and phosphatidyl-inositol, and in regulating the synthesis of glutamate. Cerebellectomy eliminates the motor syndrome and rescues animals from juvenile lethality. In the $\mathrm{df} / \mathrm{dt}$ mouse model, neuronal degeneration results from loss of a cytolinker protein (dystonin), which is expressed in the central and peripheral nervous systems and resembles the proposed function of torsinA (73). The tottering mice carry a homozygous mutation in a P/Q-type calcium channel expressed abundantly within Purkinje cells (10). The animals exhibit episodic dyskinetic attacks reminiscent of the attacks experienced by patients with paroxysmal non-kinesigenic dyskinesia (2). At the most advanced stages of attacks, tottering mice assume prolonged twisting postures involving the whole body and a mild ataxia. Lethargic mice also exhibit paroxysmal dyskinesia triggered by procedures that promote motor activity (12). In these animals, cytochrome oxydase histochemistry revealed increased activity in the red nucleus. Surgical removal of the cerebellum worsens ataxia but improved dyskinesias.

Thus, lesions of the cerebellum in rodents models of dystonia abolish the motor disorder suggesting that the cerebellum is necessary for the expression of dystonia (12). Morevover, it was shown in the $\mathrm{dt}$ rat that abnormal signaling in cerebellar cortex can lead to abnormal cerebellar output $(11,74)$. Moreover, microinjections of low doses of kainic acid into the cerebellar vermis of the mice elicited reliable and reproductible dystonic postures of the trunk and limbs (75). Peripheral administration of 3-nitropropionic acid to rodents, as in the primate, induced a dystonic phenotype associated to striatal lesions (76). In comparison with controls, hMT1 mice show increased glucose utilization (GU) in the inferior olive (IO) medial nucleus (IOM), IO dorsal accessory nucleus and substantia nigra compacta, and decreased GU in the medial globus pallidus (MGP) and lateral globus pallidus (77). They also showed increased CO activity in the IOM and Purkinje cell layer of cerebellar cortex, and decreased $\mathrm{CO}$ activity in the caudal caudate-putamen, substantia nigra reticulata and MGP. These findings suggest that the DYT1 carrier state increases energy demand in the olivocerebellar network and the IO may be a pivotal node for abnormal basal gangliacerebellar interactions in dystonia (77).

The dtSZ/dtSZ hamster, which manifests as an autosomal recessive condition with episodes of generalized dystonia induced by stress is a robust model of paroxysmal non-kinesigenic dyskinesias $(78,79)$. Attacks can last for hours and appear to be age-dependent (10). A line of evidence suggests a GABA-mediated neurotransmission defect and drugs that target these molecules are able to relieve the dystonic symptoms (80). The dtSZ hamster also exhibit highly irregular pattern of electrical activity within the striatum and globus pallidus (81).

The interaction between the basal ganglia and cerebellum in the expression of dystonic movement has been studies in two rodent models of dystonia (82). One of the model 
involved tottering mice, the other one was obtained by local application of kainic acid into the cerebellar cortex. Subthreshold lesions of the striatum exaggerated dystonic attacks in both models. In tottering mice, microdyalisis of the striatum revealed that dystonic attacks were associated with a significant reduction in extracellular dopamine. This interesting result demonstrates the functional interactions between cerebellar and basal ganglia circuits in dystonia.

However, some forms of focal dystonia could be related to different mechanisms. Blepharospasm corresponds to involuntary spasms of bilateral eyelid closure. The increased spontaneous blink rate may result from the increased excitability of the trigeminal system which is dependent on the basal ganglia $(83,84)$. It seems that reduction in dopamine induces a reduction in nucleus raphe magnus activity via the subtantia nigra pars reticulata and superior colliculus $(85,86)$. Schicatano and collegues created a two component model of benign blepharospasm based on the combination of a permissive condition (dopamine depletion) and a precipitating event (corneal irritation and dry eye caused by partial lesion of the zygomatic branch of the facial nerve). They considered that spasms of eye lid closure was an exaggeration of the normally compensatory process evoked by eye irritation (87). In this situation, there was a dysfunctional sensorimotor integration in which the central nervous system either misinterpret sensory signals or misrepresents the desired movement.

Taken as a whole most of these rodent models reveal that dysfunctional cerebellar output is sufficient for the expression of generalized dystonia. However, it is important to be aware that the organization and physiology of the central nervous system is quite different between rodents and primates. For instance, the main basal ganglia output structure is represented by the subtantia nigra pars reticulata $(\mathrm{SNr})$ in the rodent, a region involved in the control of the axial musculature, whereas it is the internal pallidum (GPi) in the primate, a region associated with the development of sophisticated hand dexterity. It is likely that the respective roles of the basal ganglia and cerebellum in motor control are different between rodents and primates.

\section{Loss of inhibitory control}

Electrophysiological studies are easier to perform in humans than in animals but must be based on non invasive techniques that limits exploration to a specific brain region. Two main techniques have been used : 1) Transcranial magnetic stimulation (TMS) of the cerebral cortex, 2) neuronal recordings in the basal ganglia during surgery.

Concerning the TMS, an excellent review has been recently proposed (Hallett, 2011) and here we we will only focus on specific segments. A line of evidence suggests that inhibition processes are defective during movement execution in dystonia. The loss of selectivity and overflow of muscular activity to muscles not usually involved in the on-going movement is clearly increased by voluntary action $(3,14,88,89)$. TMS allowed to show a decrease in both intra-cortical inhibition and silent period $(3,4)$. The coupling of a peripheral stimulation delivered prior to TMS shocks (PAS) at different intervals between the two stimuli also revealed an abnormal inhibition in dystonia $(3,8,90,91)$. As mentionned by Hallett (3), the results obtained with TMS are valuable, but they remain at a phenomenological level and focused the primary cortex whereas there have been only few data reporting stimulation of the premotor cortex (92) or cerebellum (93). 
While dystonia is mainly a motor problem, mild sensory abnormalities have been reported in patients with hand dystonia both in the spatial (94-97) and temporal (98-100) domains. Kinesthesia is also impaired (101-103) and abnormal somatotopy was demonstrated by somatosensory evoked potential mapping based on EEG (94), MEG $(94,104,105)$ and fMRI (106-108). As for motor control, a loss of lateral inhibition in sensory processing in space and time was reported (109-111). Moreover, the existence of bilateral abnormalities in the dystonic and non dystonic sides, suggests that this phenomenon is an endophenotypic trait (104) leading to changes in sensorimotor integration $(3,105)$.

Single unit recording of pallidal or thalamic nucleii have been performed in dystonic patients candidate to deep brain stimulation (DBS). They revealed interesting but contradictory data. A trend for low firing rate with a bursty pattern and oscillations was reported in the internal pallidum (112-116) and subthalamic nucleus (117). However, the role of anaesthesia was debated because some authors found no difference between dystonic and PD patients $(118,119)$. The current pathophysiological model of dystonia was also questioned by data showing that pallidal DBS was able to inihibit a subpopulation of motor thalamic neurons (120) and the abscence of difference between GPe and GPi firing rate (119). However, clear correlation between abnormal neuronal activitiy and EMG activity was reported in the basal ganglia and thalamus of patients with dystonia (116, 121-123). Moreover, single unit recording performed in cerebellar relays of the thalamus revealed abnormal firing pattern and increased response to peripheral inputs in dystonic patients (123-125). The technique of local field potentials (LFPs) allows to study local populations of neurons within a given brain region. Low oscillatory activity was recorded in the GPi of dystonic patients (126). This activity was found to be correlated with dystonic EMG (112, $114,127)$ and single unit neuronal activity $(112,128)$. The conclusion was that the frequency of synchronization in the basal ganglia is a critical problem in dystonia, as in other movement disorders (129).

Thus, electrophysiological data revealed an impaired surround inhibition in several régions including the cerebral cortex, thalamus and basal ganglia with a trend for low and bursty firing rate in the GPi in line with the current models of dystonia $(18,19,59)$. It is noteworthy that an abnormal pattern in the thalamus was observed in relays receiving cerebellar inputs (124).

\section{Neuronal networks (imaging data)}

Most of structural MRIs studies failed to show robust evidence of neural degeneration in patients with primary dystonia (130) although subtle grey and white matter micro-structural alterations were reported (131). Contradictory results have been found with voxel-based morphometry. Some studies noticed increased volumes in the sensorimotor cortex (132), putamen (133), globus pallidus (134) and cerebellum (135), but other decreased volumes in the putamen (136) sensorimotor cortex (137), cerebellum and thalamus $(136,137)$. These results must be interpreted in a phenomenological perspective since dfferent types of dystonia may yield different results.

Diffusion-weighted imaging (DWI) is sensitive to the random motion of water molecules and provide an estimate of the micro-structural integrity of the brain parenchyma and the directionality of molecular diffusion. The last parameter, also called anisotropy, is measured 
using indices such as fractional anisotropy (FA). Changes in FA are interpreted as "microstructural" changes in axonal amounts, axonal integrity, myelination, and has also been used to trace specific fiber tracts and to quantify abnormalities along them (4). DTI tractography is interesting in primary dystonia because this neurodevelopment disorder might disrupt cortico-striatal and/or cerebello-thalamic pathways. Indeed, abnormalities have been reported in the cortex (138-140), basal ganglia $(141,142)$, internal capsule $(143)$, or thalamocortical pathways (144).

Initial PET studies with [015]H2O revealed an overactivity in the cerebral cortex (particularly the rostral supplementary motor area i.e. pre-SMA), basal ganglia, cerebellum, and thalamus. The role of the caudal supplementary motor area (SMAp) and primary sensorymotor cortex was debated. Metabolism was deceased during execution of a learned movement (145-147) but increased when primary dystonia occurs at rest or in secondary dystonia (148). These abnormalities were also found in non-symptomatic patients carrying the DYT1 gene (149). In line with electrophysiological studies, abnormal sensory processing was reported in focal hand dystonia (150), blepharospasm (151), and cervical dystonia (152). Similar results were also obtained in non-manifesting DYT1 carriers $(153,154)$. The loss of inhibition in motor control was supported by the finding that an impaired GABA was observed in the striatum of dystonic patients (155).

The involvement of the dopaminergic system in primary dystonia was also demontrated with imaging techniques. Indeed, reduced D2 receptor availability in the striatum was reported in DYT1 (156-160) as well as in DYT6 patients (158). This data is compatible with dysfunction or loss of D2-bearing neurons, increased synaptic dopamine levels, or both. These changes, which may be present to different degrees in the DYT1 and DYT6 genotypes, are likely to represent susceptibility factors for the development of clinical manifestations. Moreover, abnormalities in motor sequence learning associated with increased cerebellar activation during task performance was observed in non-manifesting carriers of the DYT1 and DYT6 mutation but did not correlate with striatal D2 receptor binding (161). In a recent study, sequence learning deficits and concomitant increases in cerebellar activation were found to be specific features of the DYT1 genotype versus DYT6 carriers (162).

Disruption in information processing within the cortico-striato-pallido-thalamo-cortical and cerebello-thalamo-cortical pathways at rest was analyzed using sophisticated statistical tools (5). FDG-PET studies revealed abnormal functional connectivity with a specific pattern characterized by relative increase of metabolic activity in the posterior putamen/globus pallidus, cerebellum and SMA in DYT1 patients. In DYT6 patients, slight different results were obtained since opposite patterns of tracer uptake in the putamen were observed (154, 163, 164). In blepharospasm, there was a predominent role of the thalamus and midbrain/brainstem rather than basal ganglia and cortex. Thus, it appears clearly that different types of dystonia may be associated with different metabolic patterns (5).

Among a larger number of fMRI studies, the most commonly affected regions included various portions of the cerebral cortex, basal ganglia, and cerebellum (4, 5). Most studies reported either normal or increased basal ganglia activation during motor or sensory tasks. In the cortex, activation level was variably altered, depending on the task, the type of dystonia, and whether patients expressed dystonia during task performance or not. The primary sensory cortex was activated frequently (165-167) but not always $(107,166,168)$. 
Dystonic movements were commonly associated with overactivation in the sensorimotor cortex $(166,167,169,170)$, whereas activation levels may be normal (171) or decreased (168) during non-dystonic movements. However, reduced sensorimotor activation also may occur during dystonic movements $(165,166)$. The abnormal fMRI signals for representation of digits in the primary sensory cortex $(107,108)$ or other body parts in the basal ganglia $(171)$ have been interpreted as a loss of neuronal selectivity. It is noteworthy that although fMRI presumably monitors neuronal activation, results only partially correlate with PET studies of blood flow.

Thus, imaging studies point to the role of combined corticostriatal and cerebellar pathways in the pathophysiology of dystonia. Anatomical disruption of the cerebellar outflow was found in non manifesting carriers and manifesting mutation carriers, and a second downstream disruption in thalamo-cortical projections appeared clinically protective in non-manifestationg carriers (5).

\section{Plasticity in dystonia: A central mechanism}

Dystonia seems to be a motor circuit disorder rather than an abnormality of a specific brain region (7). There are lines of evidences showing that dytonia is associated with abnormal plasticity $(6,172-174)$. On a phenomenological point of view, primary dystonia, appears in the young age when procedural motor learning and plasticity are optimal $(6,172-174)$. Even in secondary dystonia, the delayed appearence of symptoms after brain lesion suggests some form of plasticity $(175)$ as well as the delayed therapeutic effect of pallidal stimulation in primary dystonia $(176,177)$. Long term potentiation (LTP) and long term depression (LTD) are the most widely recognized physiological models of plasticity. In humans, the physiological basis of LTP and LTD is limited to TMS and transcranial direct current stimulation (TDCS) of the cerebral cortex (7). Two main techiques have been used to study plasticity at the cortical level: repetitive TMS (rTMS) with variable frequencies inducing either LTP or LTD $(172,178)$ and paired-associative stimulation (PAS) combining electrical stimulation of a peripheral nerve and cortical TMS $(172,179,180)$. It was shown that the sensorimotor cortex (SM) exhibited an exaggerated responsiveness to rTMS responding protocols $(90,181-184)$. Associative plasticity (LTP, LTD, PAS) is enhanced with a loss of spatial specificity explained by a failure of surround inhibition (3, 7). Morever, somatosensory evoked response in SM was more enhanced by PAS in dystonic patients than in normal controls (182) revealing an increased susceptibility to peripheral events. Another way to test cortical plasiticity is to use theta burst stimulation (TBS) which relies on short trains of pulses $(5 \mathrm{~Hz})$ with an high intra-burst frequency $(50 \mathrm{~Hz})$. TBS after-effect was enhanced in dystonic patients but not in their symptomatic relatives (185). Moreover, in dystonic patients, cortical responses to $1 \mathrm{~Hz}$ rTMS is unaffected by pre-conditionning with anodal TDCS contrarily to normal controls $(179,181)$. In dystonia, there would be an increased tendency to form associations between sensory inputs and motor inputs which may lead to de-differentiation of motor representations in accordance with the theory of synaptic homeostatis $(7,186,187)$.

The question remains to whether the loss of surround inhibition and synaptic homeostasis is a trait of the whole sensorimotor system or the result of dysfuntionning of specific regions such as the striatum and the cerebellum. The processing of sensory inputs is for instance altered either in the basal ganglia (187), the thalamus (124) and cerebral cortex (3). 
Moreover, pharmacological manipulations of the thalamus induce immediate changes in the receptive fields of thalamic neurons (58) probably mimicking the effect of plasticity occuring in dystonic patients. Thus, abnormal plasticity seems to be an endophenotypic trait of dystonia $(6,7,179)$.

Several lines of evidence suggest that dystonic symptoms are generated by an abnormal functionning of the putamen, a basal ganglia region involved in motor control (188). The striatofugal medium spiny cells (MSC) receive strong cortical glutamatergic inputs and represent the main projection neurons of the striatum. They are modulated by a complex interneuronal network in which local cholinergic interneurons (Ach-I), GABAergic interneurons and mesencephalic dopaminergic inputs play critical roles. In the current accepted model of dystonia, there is an imbalance between the direct and indirect striatopallidal output pathways (189). Use-dependent long lasting changes in synaptic efficacy at cortico-striatal synpases has been proposed as a model of motor learning and memory (7). As in humans, LTP and LTD can be obtained by high frequency stimulation of corticostriatal afferents. Moreover, LTP can be reversed by low frequency afferent stimulation (synaptic depotentiation). These phenomena are modulated by striatal interneurons. A series of elegant experiments performed in a rodent genetic model of DYT1 dystonia recently revealed the close interaction between cholinergic and dopaminergic transmission $(68,190,191)$. In trangenic mice expression of the mutant form of the torsinA, increased long-term potentiation (LTP) but decreased long-term depression (LTD) and depotentiation (SD). Hence, these phenomena were reversed by lowering endogenous Ach level or by antagonizing muscarinic M1 receptors (191). On the other hand, no difference was found in electrophysiological and morphological characteristics of MSC and Ach-I between mutant and non-mutant mice $(190,191)$. These results may provide an explanation for the efficacy of anticholinergic drugs in dystonia. Thus, long-term modifications of synaptic strength at the cortico-striatal synapse exhibit a highly dynamic organization ensuring the maintenance of a synaptic homeostasis within basal ganglia circuitry (7).

As we saw previously, strong evidences have recently emerged suggesting that the cerebellum also actively contributes to the pathophysiology of dystonia. Indeed, dystonia can be associated with cerebellar dysfunction in different forms of genetic ataxia and the neuronal network involved in primary dystonia consistently encompasses the cerebellum (4, 5). Conversely, the cerebellum has the ability to inhibit cortical activity, control sensorimotor integration and play a part in maladaptative neural plasticity (4). The fundamental mechanism may be the ability of the cerebellum to control cortico-striatal long-term depression, a mechanism thought to underlie neural plasticity. As previously noticed, the paradox is that most of genetic rodent model of dystonia associated with cerebellar dysfunctionning do not exhibit a clear phenotype of dystonia (2).

\section{Conclusion and perspectives}

Primary dystonia is a developement disorder with a strong genetic basis but the phenotype is likely to be triggered by risk factors such as environment insults, increased sensory inputs or physiological stress (2). Several lines of evidence suggest that dystonia corresponds to a disruption in the homeostatic regulation of neural plasticity within the sensorimotor circuitry $(1,3)$. However, the term dystonia encompasses a broad spectrum of disease and it is important to take up its pathophysiology on the basis of clear phenomenological 
considerations. In addition, different pathophysiological mechanisms may underlie similar phenotypes whereas different genotypes (e.g. DT6 and DYT1) may share similar functional abnormalities (1).

Imaging data support the hypotheses of the respective roles of basal ganglia and cerebellum by showing that dystonia disrupts the whole motor circuits involved in motor learning (5). Disruption in surround inhibition and aberrant plasticity are critical features of dystonia but we do not know whether this phenomenon occurs in a critical region (striatum, cerebellum) or is a feature of the whole sensorimotor network. How and where cerebellar circuits interact with basal ganglia circuits still remains a partially unsolved question. The thalamus which receive inputs from both systems in anatomically close nucleii could potentially play a critical rôle in the intégration of pallidal and cerbellar inputs. Indeed, disruption in sensory information and increased activity were reported in this region either in dystonic patients and in a primate model of the disease.

We began to have an idea of the disrupted networks within the striatum based on experimental models of dystonia showing that plasticity is impaired by an abnormal functionning of acetylcholine interneurones and their paradoxical response to D2 dopaminergic stimulation (7). The net result is a disequilibrium between LTP and LTD, the bases of plasticity at the cortico-striatal synapsis. The impairment of surround inhibition could also be related to decreased GABA transmission within the striatum as suggested by data obtained in human patients $(3,155)$ but also by the loss of parvalbumin-reactive GABArgic interneurones in a hamster model of paroxysmal dystonia (192). The cellular mechanisms leading to a dysfunctionning of the cerebellum remains less clear but some observations in rodent models suggest a possible dysfunctionning of Purkinje cells potentially related to some forms of channelopathy (11). Thus, animal models are promising although none of them can perfectly mimic the complexity of the clinical features observed in humans $(1,12)$. A problem in the genotypic rodent models is that they do not induce a phenotypic of dystonia. As stated above, it is possible that this discrepancy is due to the different organization of the subcortico-cortical networks between rodents and primates. However, the rodent models may be particularly challenging to make the gap between genes and the functional brain abnormalitites associated with primary dystonia (2). They can also be useful to develop experimental therapeutics. In primates, most models have focused on basal ganglia dysfunction. However, the elegant model proposed by Mink several years ago on this basis $(18,189)$ still lacks a direct experimental demonstration in the monkey. It will be probably necessary in the near future to develop more sophisticated models of dystonia in the sub-human primate to test directly some pathophysiological hypotheses concerning the disruption of information processing within the striato-pallidal and/or cerebello-cortical pathways.

Finally, a great challenge will be to understand how the ubiquitous cellular mechanisms disrupted by genetic mutations might explain the focal phenotypic expression of dystonia. As recently pointed by Pisani and collegues, dystonia would represent a high priority for medical reseach in the field of movement disorders for several reasons (193). First, this pathological model is unique because it represents a window to study the role of plasticity in the development of the central nervous system. Second, it provides the opportunity to explore the subtle interactions between the basal ganglia and cerebellum networks in motor control. Third, there is a fascinating challenge to undestand how the genetic defects will be 
translated into phenotypic effects. Finally, the development of new therapeutics may necessitate novel strategies based on original technologies. There is no doubt that a large collaboration of scientists with different expertises will be necessary to achieve this goal.

\section{References}

[1] Vidailhet M, Grabli D, Roze E. Pathophysiology of dystonia. Curr Opin Neurol 2009;22:406-413.

[2] Breakefield XO, Blood AJ, Li Y, Hallett M, Hanson PI, Standaert DG. The pathophysiological basis of dystonias. Nat Rev Neurosci 2008;9:222-234.

[3] Hallett M. Neurophysiology of dystonia: The role of inhibition. Neurobiol Dis 2011;42:177-184.

[4] Neychev VK, Gross RE, Lehericy S, Hess EJ, Jinnah HA. The functional neuroanatomy of dystonia. Neurobiol Dis 2011;42:185-201.

[5] Niethammer M, Carbon M, Argyelan M, Eidelberg D. Hereditary dystonia as a neurodevelopmental circuit disorder: Evidence from neuroimaging. Neurobiol Dis 2011;42:202-209.

[6] Peterson DA, Sejnowski TJ, Poizner H. Convergent evidence for abnormal striatal synaptic plasticity in dystonia. Neurobiol Dis 2010;37:558-573.

[7] Quartarone A, Pisani A. Abnormal plasticity in dystonia: Disruption of synaptic homeostasis. Neurobiol Dis 2011;42:162-170.

[8] Quartarone A, Rizzo V, Morgante F. Clinical features of dystonia: a pathophysiological revisitation. Curr Opin Neurol 2008;21:484-490.

[9] Guehl D, Cuny E, Ghorayeb I, Michelet T, Bioulac B, Burbaud P. Primate models of dystonia. Prog Neurobiol 2009;87:118-131.

[10] Jinnah HA, Hess EJ, Ledoux MS, Sharma N, Baxter MG, Delong MR. Rodent models for dystonia research: characteristics, evaluation, and utility. Mov Disord 2005;20:283-292.

[11] LeDoux MS. Animal models of dystonia: Lessons from a mutant rat. Neurobiol Dis 2011;42:152-161.

[12] Raike RS, Jinnah HA, Hess EJ. Animal models of generalized dystonia. NeuroRx 2005;2:504-512.

[13] Fahn S. Concept and classification of dystonia. Adv Neurol 1988;50:1-8.

[14] Hallett M. Dystonia: abnormal movements result from loss of inhibition. Adv Neurol 2004;94:1-9.

[15] Calne DB, Lang AE. Secondary dystonia. Adv Neurol 1988;50:9-33.

[16] Bhatia KP, Bhatt MH, Marsden CD. The causalgia-dystonia syndrome. Brain 1993;116 ( Pt 4):843-851.

[17] Perlmutter JS, Tempel LW, Black KJ, Parkinson D, Todd RD. MPTP induces dystonia and parkinsonism. Clues to the pathophysiology of dystonia. Neurology 1997;49:1432-1438.

[18] Mink JW. The Basal Ganglia and involuntary movements: impaired inhibition of competing motor patterns. Arch Neurol 2003;60:1365-1368.

[19] Mink JW. Abnormal circuit function in dystonia. Neurology 2006;66:959.

[20] Malouin F, Bedard PJ. Frontal torticollis (head tilt) induced by electrolytic lesion and kainic acid injection in monkeys and cats. Exp Neurol 1982;78:551-560.

[21] Klier EM, Wang H, Constantin AG, Crawford JD. Midbrain control of threedimensional head orientation. Science 2002;295:1314-1316. 
[22] Schmied A, Amalric M, Dormont JF, Farin D. GABAergic mechanisms in the cat red nucleus: effects of intracerebral microinjections of muscimol or bicuculline on a conditioned motor task. Exp Brain Res 1990;81:523-532.

[23] van't Groenewout JL, Stone MR, Vo VN, Truong DD, Matsumoto RR. Evidence for the involvement of histamine in the antidystonic effects of diphenhydramine. Exp Neurol 1995;134:253-260.

[24] Burke RE, Fahn S. An evaluation of sustained postural abnormalities in rats induced by intracerebro-ventricular injection of chlorpromazine methiodide or somatostatin as models of dystonia. Adv Neurol 1988;50:335-342.

[25] Casey DE, Gerlach J, Christensson E. Dopamine, acetylcholine, and GABA effects in acute dystonia in primates. Psychopharmacology (Berl) 1980;70:83-87.

[26] Heintz R, Casey DE. Pargyline reduces/prevents neuroleptic-induced acute dystonia in monkeys. Psychopharmacology (Berl) 1987;93:207-213.

[27] Povlsen UJ, Noring U, Laursen AL, Korsgaard S, Gerlach J. Effects of serotonergic and anticholinergic drugs in haloperidol-induced dystonia in Cebus monkeys. Clin Neuropharmacol 1986;9:84-90.

[28] Jenner P, Clow A, Reavill C, Theodorou A, Marsden CD. Stereoselective actions of substituted benzamide drugs on cerebral dopamine mechanisms. J Pharm Pharmacol 1980;32:39-44.

[29] Casey DE. Extrapyramidal syndromes in nonhuman primates: typical and atypical neuroleptics. Psychopharmacol Bull 1991;27:47-50.

[30] Casey DE. Dopamine D1 (SCH 23390) and D2 (haloperidol) antagonists in drug-naive monkeys. Psychopharmacology (Berl) 1992;107:18-22.

[31] Lublin H, Gerlach J, Morkeberg F. Long-term treatment with low doses of the D1 antagonist NNC 756 and the D2 antagonist raclopride in monkeys previously exposed to dopamine antagonists. Psychopharmacology (Berl) 1994;114:495-504.

[32] Barany S, Haggstrom JE, Gunne LM. Application of a primate model for tardive dyskinesia. Acta Pharmacol Toxicol (Copenh) 1983;52:86-89.

[33] Kistrup K, Gerlach J. Selective D1 and D2 receptor manipulation in Cebus monkeys: relevance for dystonia and dyskinesia in humans. Pharmacol Toxicol 1987;61:157161.

[34] Klintenberg R, Gunne L, Andren PE. Tardive dyskinesia model in the common marmoset. Mov Disord 2002;17:360-365.

[35] Marsden CD, Jenner P. The pathophysiology of extrapyramidal side-effects of neuroleptic drugs. Psychol Med 1980;10:55-72.

[36] Gerlach J, Bjorndal N, Christensson E. Methylphenidate, apomorphine, THIP, and diazepam in monkeys: dopamine-GABA behavior related to psychoses and tardive dyskinesia. Psychopharmacology (Berl) 1984;82:131-134.

[37] Peacock L, Lublin H, Gerlach J. The effects of dopamine D1 and D2 receptor agonists and antagonists in monkeys withdrawn from long-term neuroleptic treatment. Eur J Pharmacol 1990;186:49-59.

[38] Peacock L, Jensen G, Nicholson K, Gerlach J. Extrapyramidal side effects during chronic combined dopamine D1 and D2 antagonist treatment in Cebus apella monkeys. Eur Arch Psychiatry Clin Neurosci 1999;249:221-226.

[39] Burbaud P, Bonnet B, Guehl D, Lagueny A, Bioulac B. Movement disorders induced by gamma-aminobutyric agonist and antagonist injections into the internal globus pallidus and substantia nigra pars reticulata of the monkey. Brain Res 1998;780:102107. 
[40] Boyce S, Clarke CE, Luquin R, et al. Induction of chorea and dystonia in parkinsonian primates. Mov Disord 1990;5:3-7.

[41] Crossman AR, Sambrook MA. Experimental torticollis in the monkey produced by unilateral 6-hydroxy-dopamine brain lesions. Brain Res 1978;149:498-502.

[42] Mitchell IJ, Luquin R, Boyce S, et al. Neural mechanisms of dystonia: evidence from a 2-deoxyglucose uptake study in a primate model of dopamine agonist-induced dystonia. Mov Disord 1990;5:49-54.

[43] Page RD. The use of thalamotomy in the treatment of levodopa-induced dyskinesia. Acta Neurochir (Wien) 1992;114:77-117.

[44] Page RD, Sambrook MA, Crossman AR. Thalamotomy for the alleviation of levodopainduced dyskinesia: experimental studies in the 1-methyl-4-phenyl-1,2,3,6tetrahydropyridine-treated parkinsonian monkey. Neuroscience 1993;55:147-165.

[45] Pearce RK, Jackson M, Britton DR, Shiosaki K, Jenner P, Marsden CD. Actions of the D1 agonists A-77636 and A-86929 on locomotion and dyskinesia in MPTP-treated L-dopa-primed common marmosets. Psychopharmacology (Berl) 1999;142:51-60.

[46] Pearce RK, Jackson M, Smith L, Jenner P, Marsden CD. Chronic L-DOPA administration induces dyskinesias in the 1-methyl-4- phenyl-1,2,3,6tetrahydropyridine-treated common marmoset (Callithrix Jacchus). Mov Disord 1995;10:731-740.

[47] Galvan A, Villalba RM, West SM, et al. GABAergic modulation of the activity of globus pallidus neurons in primates: in vivo analysis of the functions of GABA receptors and GABA transporters. J Neurophysiol 2005;94:990-1000.

[48] Yamada H, Fujimoto K, Yoshida M. Neuronal mechanism underlying dystonia induced by bicuculline injection into the putamen of the cat. Brain Res 1995;677:333-336.

[49] Worbe Y, Baup N, Grabli D, et al. Behavioral and movement disorders induced by local inhibitory dysfunction in primate striatum. Cereb Cortex 2009;19:1844-1856.

[50] Darbin O, Wichmann T. Effects of striatal GABA A-receptor blockade on striatal and cortical activity in monkeys. J Neurophysiol 2008;99:1294-1305.

[51] Worbe Y, Epinat J, Feger J, Tremblay L. Discontinuous Long-Train Stimulation in the Anterior Striatum in Monkeys Induces Abnormal Behavioral States. Cereb Cortex 2011.

[52] Lehericy S, Grand S, Pollak P, et al. Clinical characteristics and topography of lesions in movement disorders due to thalamic lesions. Neurology 2001;57:1055-1066.

[53] Lehericy S, Vidailhet M, Dormont D, et al. Striatopallidal and thalamic dystonia. A magnetic resonance imaging anatomoclinical study. Arch Neurol 1996;53:241-250.

[54] Hoover JE, Strick PL. The organization of cerebellar and basal ganglia outputs to primary motor cortex as revealed by retrograde transneuronal transport of herpes simplex virus type 1. J Neurosci 1999;19:1446-1463.

[55] Matelli M, Luppino G. Thalamic input to mesial and superior area 6 in the macaque monkey. J Comp Neurol 1996;372:59-87.

[56] Steriade M. Impact of network activities on neuronal properties in corticothalamic systems. J Neurophysiol 2001;86:1-39.

[57] Guehl D, Burbaud P, Boraud T, Bioulac B. Bicuculline injections into the rostral and caudal motor thalamus of the monkey induce different types of dystonia. Eur J Neurosci 2000;12:1033-1037. 
[58] Macia F, Escola L, Guehl D, Michelet T, Bioulac B, Burbaud P. Neuronal activity in the monkey motor thalamus during bicuculline-induced dystonia. Eur J Neurosci 2002;15:1353-1362.

[59] Berardelli A, Rothwell JC, Hallett M, Thompson PD, Manfredi M, Marsden CD. The pathophysiology of primary dystonia. Brain 1998;121 ( Pt 7):1195-1212.

[60] Byl NN. What can we learn from animal models of focal hand dystonia? Rev Neurol (Paris) 2003;159:857-873.

[61] Byl NN, Merzenich MM, Cheung S, Bedenbaugh P, Nagarajan SS, Jenkins WM. A primate model for studying focal dystonia and repetitive strain injury: effects on the primary somatosensory cortex. Phys Ther 1997;77:269-284.

[62] Topp KS, Byl NN. Movement dysfunction following repetitive hand opening and closing: anatomical analysis in Owl monkeys. Mov Disord 1999;14:295-306.

[63] Blake DT, Strata F, Churchland AK, Merzenich MM. Neural correlates of instrumental learning in primary auditory cortex. Proc Natl Acad Sci U S A 2002;99:10114-10119.

[64] Sharma N, Baxter MG, Petravicz J, et al. Impaired motor learning in mice expressing torsinA with the DYT1 dystonia mutation. J Neurosci 2005;25:5351-5355.

[65] Shashidharan P, Sandu D, Potla U, et al. Transgenic mouse model of early-onset DYT1 dystonia. Hum Mol Genet 2005;14:125-133.

[66] Dang MT, Yokoi F, McNaught KS, et al. Generation and characterization of Dyt1 DeltaGAG knock-in mouse as a model for early-onset dystonia. Exp Neurol 2005;196:452-463.

[67] Goodchild RE, Kim CE, Dauer WT. Loss of the dystonia-associated protein torsinA selectively disrupts the neuronal nuclear envelope. Neuron 2005;48:923-932.

[68] Pisani A, Martella G, Tscherter A, et al. Altered responses to dopaminergic D2 receptor activation and $\mathrm{N}$-type calcium currents in striatal cholinergic interneurons in a mouse model of DYT1 dystonia. Neurobiol Dis 2006;24:318-325.

[69] Sato K, Sumi-Ichinose C, Kaji R, et al. Differential involvement of striosome and matrix dopamine systems in a transgenic model of dopa-responsive dystonia. Proc Natl Acad Sci U S A 2008;105:12551-12556.

[70] Balcioglu A, Kim MO, Sharma N, Cha JH, Breakefield XO, Standaert DG. Dopamine release is impaired in a mouse model of DYT1 dystonia. J Neurochem 2007;102:783788.

[71] Lorden JF, McKeon TW, Baker HJ, Cox N, Walkley SU. Characterization of the rat mutant dystonic $(\mathrm{dt})$ : a new animal model of dystonia musculorum deformans. J Neurosci 1984;4:1925-1932.

[72] Xiao J, Ledoux MS. Caytaxin deficiency causes generalized dystonia in rats. Brain Res Mol Brain Res 2005;141:181-192.

[73] Young KG, De Repentigny Y, Kothary R. Re: "A possible cellular mechanism of neuronal loss in the dorsal root ganglia of dystonia musculorum ( $\mathrm{dt}$ ) mice". J Neuropathol Exp Neurol 2007;66:248-249; author reply 249.

[74] Campbell RM, Peterson AC. An intrinsic neuronal defect operates in dystonia musculorum: a study of $\mathrm{dt} / \mathrm{dt}<==>+/+$ chimeras. Neuron 1992;9:693-703.

[75] Pizoli CE, Jinnah HA, Billingsley ML, Hess EJ. Abnormal cerebellar signaling induces dystonia in mice. J Neurosci 2002;22:7825-7833.

[76] Fernagut PO, Diguet E, Stefanova N, et al. Subacute systemic 3-nitropropionic acid intoxication induces a distinct motor disorder in adult C57Bl/ 6 mice: behavioural and histopathological characterisation. Neuroscience 2002;114:1005-1017. 
[77] Xiao J, Zhao Y, Bastian RW, et al. The c.-237_236GA>TT THAP1 sequence variant does not increase risk for primary dystonia. Mov Disord 2011;26:549-552.

[78] Richter A, Loscher W. Pathology of idiopathic dystonia: findings from genetic animal models. Prog Neurobiol 1998;54:633-677.

[79] Richter A, Loscher W. Animal models of paroxysmal dystonia. Adv Neurol 2002;89:443-451.

[80] Sander SE, Richter A. Effects of intrastriatal injections of glutamate receptor antagonists on the severity of paroxysmal dystonia in the dtsz mutant. Eur J Pharmacol 2007;563:102-108.

[81] Kohling R, Koch UR, Hamann M, Richter A. Increased excitability in cortico-striatal synaptic pathway in a model of paroxysmal dystonia. Neurobiol Dis 2004;16:236245.

[82] Neychev VK, Fan X, Mitev VI, Hess EJ, Jinnah HA. The basal ganglia and cerebellum interact in the expression of dystonic movement. Brain 2008;131:2499-2509.

[83] Evinger C. Animal models of focal dystonia. NeuroRx 2005;2:513-524.

[84] Evinger C, Bao JB, Powers AS, et al. Dry eye, blinking, and blepharospasm. Mov Disord 2002;17 Suppl 2:S75-78.

[85] Basso MA, Evinger C. An explanation for reflex blink hyperexcitability in Parkinson's disease. II. Nucleus raphe magnus. J Neurosci 1996;16:7318-7330.

[86] Basso MA, Powers AS, Evinger C. An explanation for reflex blink hyperexcitability in Parkinson's disease. I. Superior colliculus. J Neurosci 1996;16:7308-7317.

[87] Schicatano EJ, Basso MA, Evinger C. Animal model explains the origins of the cranial dystonia benign essential blepharospasm. J Neurophysiol 1997;77:2842-2846.

[88] Obeso JA, Rothwell JC, Lang AE, Marsden CD. Myoclonic dystonia. Neurology 1983;33:825-830.

[89] Sohn YH, Voller B, Dimyan M, et al. Cortical control of voluntary blinking: a transcranial magnetic stimulation study. Clin Neurophysiol 2004;115:341-347.

[90] Quartarone A, Morgante F, Sant'angelo A, et al. Abnormal plasticity of sensorimotor circuits extends beyond the affected body part in focal dystonia. J Neurol Neurosurg Psychiatry 2008;79:985-990.

[91] Quartarone A, Rizzo V, Terranova C, et al. Abnormal sensorimotor plasticity in organic but not in psychogenic dystonia. Brain 2009;132:2871-2877.

[92] Koch G, Schneider S, Baumer T, et al. Altered dorsal premotor-motor interhemispheric pathway activity in focal arm dystonia. Mov Disord 2008;23:660-668.

[93] Ugawa Y. [Electromyographic analysis of cortical myoclonus and focal dystonia]. Rinsho Shinkeigaku 1995;35:1387-1389.

[94] Bara-Jimenez W, Catalan MJ, Hallett M, Gerloff C. Abnormal somatosensory homunculus in dystonia of the hand. Ann Neurol 1998;44:828-831.

[95] Sanger TD, Pascual-Leone A, Tarsy D, Schlaug G. Nonlinear sensory cortex response to simultaneous tactile stimuli in writer's cramp. Mov Disord 2002;17:105-111.

[96] Sanger TD, Tarsy D, Pascual-Leone A. Abnormalities of spatial and temporal sensory discrimination in writer's cramp. Mov Disord 2001;16:94-99.

[97] Serrien DJ, Burgunder JM, Wiesendanger M. Disturbed sensorimotor processing during control of precision grip in patients with writer's cramp. Mov Disord 2000;15:965-972.

[98] Bara-Jimenez W, Shelton P, Sanger TD, Hallett M. Sensory discrimination capabilities in patients with focal hand dystonia. Ann Neurol 2000;47:377-380. 
[99] Fiorio M, Tinazzi M, Bertolasi L, Aglioti SM. Temporal processing of visuotactile and tactile stimuli in writer's cramp. Ann Neurol 2003;53:630-635.

[100] Tinazzi M, Fiaschi A, Frasson E, Fiorio M, Cortese F, Aglioti SM. Deficits of temporal discrimination in dystonia are independent from the spatial distance between the loci of tactile stimulation. Mov Disord 2002;17:333-338.

[101] Frima N, Nasir J, Grunewald RA. Abnormal vibration-induced illusion of movement in idiopathic focal dystonia: an endophenotypic marker? Mov Disord 2008;23:373-377.

[102] Grunewald RA, Yoneda Y, Shipman JM, Sagar HJ. Idiopathic focal dystonia: a disorder of muscle spindle afferent processing? Brain 1997;120 ( Pt 12):2179-2185.

[103] Putzki N, Stude P, Konczak J, Graf K, Diener HC, Maschke M. Kinesthesia is impaired in focal dystonia. Mov Disord 2006;21:754-760.

[104] Meunier S, Garnero L, Ducorps A, et al. Human brain mapping in dystonia reveals both endophenotypic traits and adaptive reorganization. Ann Neurol 2001;50:521527.

[105] Meunier S, Hallett M. Endophenotyping: a window to the pathophysiology of dystonia. Neurology 2005;65:792-793.

[106] Butterworth S, Francis S, Kelly E, McGlone F, Bowtell R, Sawle GV. Abnormal cortical sensory activation in dystonia: an fMRI study. Mov Disord 2003;18:673-682.

[107] Nelson AJ, Blake DT, Chen R. Digit-specific aberrations in the primary somatosensory cortex in Writer's cramp. Ann Neurol 2009;66:146-154.

[108] Peller M, Zeuner KE, Munchau A, et al. The basal ganglia are hyperactive during the discrimination of tactile stimuli in writer's cramp. Brain 2006;129:2697-2708.

[109] Frasson E, Priori A, Bertolasi L, Mauguiere F, Fiaschi A, Tinazzi M. Somatosensory disinhibition in dystonia. Mov Disord 2001;16:674-682.

[110] Tamura Y, Matsuhashi M, Lin P, et al. Impaired intracortical inhibition in the primary somatosensory cortex in focal hand dystonia. Mov Disord 2008;23:558-565.

[111] Tinazzi M, Priori A, Bertolasi L, Frasson E, Mauguiere F, Fiaschi A. Abnormal central integration of a dual somatosensory input in dystonia. Evidence for sensory overflow. Brain 2000;123 ( Pt 1):42-50.

[112] Chen CC, Kuhn AA, Trottenberg T, Kupsch A, Schneider GH, Brown P. Neuronal activity in globus pallidus interna can be synchronized to local field potential activity over 3-12 Hz in patients with dystonia. Exp Neurol 2006;202:480-486.

[113] Liu X, Yianni J, Wang S, Bain PG, Stein JF, Aziz TZ. Different mechanisms may generate sustained hypertonic and rhythmic bursting muscle activity in idiopathic dystonia. Exp Neurol 2006;198:204-213.

[114] Sharott A, Grosse P, Kuhn AA, et al. Is the synchronization between pallidal and muscle activity in primary dystonia due to peripheral afferance or a motor drive? Brain 2008;131:473-484.

[115] Starr PA, Rau GM, Davis V, et al. Spontaneous pallidal neuronal activity in human dystonia: comparison with Parkinson's disease and normal macaque. J Neurophysiol 2005;93:3165-3176.

[116] Tang JK, Moro E, Mahant N, et al. Neuronal firing rates and patterns in the globus pallidus internus of patients with cervical dystonia differ from those with Parkinson's disease. J Neurophysiol 2007;98:720-729.

[117] Schrock LE, Ostrem JL, Turner RS, Shimamoto SA, Starr PA. The subthalamic nucleus in primary dystonia: single-unit discharge characteristics. J Neurophysiol 2009;102:3740-3752. 
[118] Hashimoto T. Neuronal activity in the globus pallidus in primary dystonia and offperiod dystonia. J Neurol 2000;247 Suppl 5:V49-52.

[119] Merello M, Cerquetti D, Cammarota A, et al. Neuronal globus pallidus activity in patients with generalised dystonia. Mov Disord 2004;19:548-554.

[120] Pralong E, Debatisse D, Maeder M, Vingerhoets F, Ghika J, Villemure JG. Effect of deep brain stimulation of GPI on neuronal activity of the thalamic nucleus ventralis oralis in a dystonic patient. Neurophysiol Clin 2003;33:169-173.

[121] Foncke EM, Bour LJ, van der Meer JN, Koelman JH, Tijssen MA. Abnormal low frequency drive in myoclonus-dystonia patients correlates with presence of dystonia. Mov Disord 2007;22:1299-1307.

[122] Tang JK, Mahant N, Cunic D, et al. Changes in cortical and pallidal oscillatory activity during the execution of a sensory trick in patients with cervical dystonia. Exp Neurol 2007;204:845-848.

[123] Zhuang P, Li Y, Hallett M. Neuronal activity in the basal ganglia and thalamus in patients with dystonia. Clin Neurophysiol 2004;115:2542-2557.

[124] Lenz FA, Suarez JI, Metman LV, et al. Pallidal activity during dystonia: somatosensory reorganisation and changes with severity. J Neurol Neurosurg Psychiatry 1998;65:767-770.

[125] Zirh TA, Reich SG, Perry V, Lenz FA. Thalamic single neuron and electromyographic activities in patients with dystonia. Adv Neurol 1998;78:27-32.

[126] Silberstein P, Kuhn AA, Kupsch A, et al. Patterning of globus pallidus local field potentials differs between Parkinson's disease and dystonia. Brain 2003;126:25972608.

[127] Chen CC, Kuhn AA, Hoffmann KT, et al. Oscillatory pallidal local field potential activity correlates with involuntary EMG in dystonia. Neurology 2006;66:418-420.

[128] Foncke EM, Bour LJ, Speelman JD, Koelman JH, Tijssen MA. Local field potentials and oscillatory activity of the internal globus pallidus in myoclonus-dystonia. Mov Disord 2007;22:369-376.

[129] Eusebio A, Brown P. Oscillatory activity in the basal ganglia. Parkinsonism Relat Disord 2007;13 Suppl 3:S434-436.

[130] Rutledge JN, Hilal SK, Silver AJ, Defendini R, Fahn S. Magnetic resonance imaging of dystonic states. Adv Neurol 1988;50:265-275.

[131] Black KJ, Ongur D, Perlmutter JS. Putamen volume in idiopathic focal dystonia. Neurology 1998;51:819-824.

[132] Garraux G, Bauer A, Hanakawa T, Wu T, Kansaku K, Hallett M. Changes in brain anatomy in focal hand dystonia. Ann Neurol 2004;55:736-739.

[133] Etgen T, Muhlau M, Gaser C, Sander D. Bilateral grey-matter increase in the putamen in primary blepharospasm. J Neurol Neurosurg Psychiatry 2006;77:1017-1020.

[134] Egger K, Mueller J, Schocke M, et al. Voxel based morphometry reveals specific gray matter changes in primary dystonia. Mov Disord 2007;22:1538-1542.

[135] Obermann M, Yaldizli O, De Greiff A, et al. Morphometric changes of sensorimotor structures in focal dystonia. Mov Disord 2007;22:1117-1123.

[136] Draganski B, Thun-Hohenstein C, Bogdahn U, Winkler J, May A. "Motor circuit" gray matter changes in idiopathic cervical dystonia. Neurology 2003;61:1228-1231.

[137] Delmaire C, Vidailhet M, Elbaz A, et al. Structural abnormalities in the cerebellum and sensorimotor circuit in writer's cramp. Neurology 2007;69:376-380.

[138] Bonilha L, de Vries PM, Vincent DJ, et al. Structural white matter abnormalities in patients with idiopathic dystonia. Mov Disord 2007;22:1110-1116. 
[139] Carbon M, Kingsley PB, Su S, et al. Microstructural white matter changes in carriers of the DYT1 gene mutation. Ann Neurol 2004;56:283-286.

[140] Carbon M, Kingsley PB, Tang C, Bressman S, Eidelberg D. Microstructural white matter changes in primary torsion dystonia. Mov Disord 2008;23:234-239.

[141] Colosimo C, Pantano P, Calistri V, Totaro P, Fabbrini G, Berardelli A. Diffusion tensor imaging in primary cervical dystonia. J Neurol Neurosurg Psychiatry 2005;76:15911593.

[142] Fabbrini G, Pantano P, Totaro P, et al. Diffusion tensor imaging in patients with primary cervical dystonia and in patients with blepharospasm. Eur J Neurol 2008;15:185-189.

[143] Delmaire C, Vidailhet M, Wassermann D, et al. Diffusion abnormalities in the primary sensorimotor pathways in writer's cramp. Arch Neurol 2009;66:502-508.

[144] Argyelan M, Carbon M, Niethammer M, et al. Cerebellothalamocortical connectivity regulates penetrance in dystonia. J Neurosci 2009;29:9740-9747.

[145] Ceballos-Baumann AO, Passingham RE, Warner T, Playford ED, Marsden CD, Brooks DJ. Overactive prefrontal and underactive motor cortical areas in idiopathic dystonia. Ann Neurol 1995;37:363-372.

[146] Eidelberg D, Moeller JR, Ishikawa T, et al. The metabolic topography of idiopathic torsion dystonia. Brain 1995;118 ( Pt 6):1473-1484.

[147] Playford ED, Passingham RE, Marsden CD, Brooks DJ. Increased activation of frontal areas during arm movement in idiopathic torsion dystonia. Mov Disord 1998;13:309-318.

[148] Ceballos-Baumann AO, Brooks DJ. Activation positron emission tomography scanning in dystonia. Adv Neurol 1998;78:135-152.

[149] Eidelberg D. Functional brain networks in movement disorders. Curr Opin Neurol 1998;11:319-326.

[150] Tempel LW, Perlmutter JS. Abnormal vibration-induced cerebral blood flow responses in idiopathic dystonia. Brain 1990;113 ( Pt 3):691-707.

[151] Feiwell RJ, Black KJ, McGee-Minnich LA, Snyder AZ, MacLeod AM, Perlmutter JS. Diminished regional cerebral blood flow response to vibration in patients with blepharospasm. Neurology 1999;52:291-297.

[152] Naumann M, Magyar-Lehmann S, Reiners K, Erbguth F, Leenders KL. Sensory tricks in cervical dystonia: perceptual dysbalance of parietal cortex modulates frontal motor programming. Ann Neurol 2000;47:322-328.

[153] Carbon M, Ghilardi MF, Argyelan M, Dhawan V, Bressman SB, Eidelberg D. Increased cerebellar activation during sequence learning in DYT1 carriers: an equiperformance study. Brain 2008;131:146-154.

[154] Carbon M, Su S, Dhawan V, Raymond D, Bressman S, Eidelberg D. Regional metabolism in primary torsion dystonia: effects of penetrance and genotype. Neurology 2004;62:1384-1390.

[155] Levy LM, Hallett M. Impaired brain GABA in focal dystonia. Ann Neurol 2002;51:93101.

[156] Asanuma K, Ma Y, Okulski J, et al. Decreased striatal D2 receptor binding in nonmanifesting carriers of the DYT1 dystonia mutation. Neurology 2005;64:347-349.

[157] Beukers RJ, Booij J, Weisscher N, Zijlstra F, van Amelsvoort TA, Tijssen MA. Reduced striatal D2 receptor binding in myoclonus-dystonia. Eur J Nucl Med Mol Imaging 2009;36:269-274. 
[158] Carbon M, Argyelan M, Eidelberg D. Functional imaging in hereditary dystonia. Eur J Neurol 2010;17 Suppl 1:58-64.

[159] Karimi M, Moerlein SM, Videen TO, et al. Decreased striatal dopamine receptor binding in primary focal dystonia: A D2 or D3 defect? Mov Disord 2010.

[160] Kishore A, Nygaard TG, de la Fuente-Fernandez R, et al. Striatal D2 receptors in symptomatic and asymptomatic carriers of dopa-responsive dystonia measured with [11C]-raclopride and positron-emission tomography. Neurology 1998;50:1028-1032.

[161] Carbon M, Niethammer M, Peng S, et al. Abnormal striatal and thalamic dopamine neurotransmission: Genotype-related features of dystonia. Neurology 2009;72:20972103.

[162] Carbon M, Argyelan M, Ghilardi MF, et al. Impaired sequence learning in dystonia mutation carriers: a genotypic effect. Brain 2011;134:1416-1427.

[163] Carbon M, Eidelberg D. Abnormal structure-function relationships in hereditary dystonia. Neuroscience 2009;164:220-229.

[164] Carbon M, Trost M, Ghilardi MF, Eidelberg D. Abnormal brain networks in primary torsion dystonia. Adv Neurol 2004;94:155-161.

[165] Dresel C, Haslinger B, Castrop F, Wohlschlaeger AM, Ceballos-Baumann AO. Silent event-related fMRI reveals deficient motor and enhanced somatosensory activation in orofacial dystonia. Brain 2006;129:36-46.

[166] Haslinger B, Erhard P, Dresel C, Castrop F, Roettinger M, Ceballos-Baumann AO. "Silent event-related" fMRI reveals reduced sensorimotor activation in laryngeal dystonia. Neurology 2005;65:1562-1569.

[167] Simonyan K, Ludlow CL. Abnormal activation of the primary somatosensory cortex in spasmodic dysphonia: an FMRI study. Cereb Cortex 2010;20:2749-2759.

[168] Oga T, Honda M, Toma K, et al. Abnormal cortical mechanisms of voluntary muscle relaxation in patients with writer's cramp: an fMRI study. Brain 2002;125:895-903.

[169] Hu XY, Wang L, Liu H, Zhang SZ. Functional magnetic resonance imaging study of writer's cramp. Chin Med J (Engl) 2006;119:1263-1271.

[170] Pujol J, Roset-Llobet J, Rosines-Cubells D, et al. Brain cortical activation during guitarinduced hand dystonia studied by functional MRI. Neuroimage 2000;12:257-267.

[171] Delmaire C, Krainik A, Tezenas du Montcel S, et al. Disorganized somatotopy in the putamen of patients with focal hand dystonia. Neurology 2005;64:1391-1396.

[172] Quartarone A, Bagnato S, Rizzo V, et al. Abnormal associative plasticity of the human motor cortex in writer's cramp. Brain 2003;126:2586-2596.

[173] Quartarone A, Sant'Angelo A, Battaglia F, et al. Enhanced long-term potentiation-like plasticity of the trigeminal blink reflex circuit in blepharospasm. J Neurosci 2006;26:716-721.

[174] Rothwell JC, Huang YZ. Systems-level studies of movement disorders in dystonia and Parkinson's disease. Curr Opin Neurobiol 2003;13:691-695.

[175] Scott BL, Jankovic J. Delayed-onset progressive movement disorders after static brain lesions. Neurology 1996;46:68-74.

[176] Vidailhet M, Vercueil L, Houeto JL, et al. Bilateral deep-brain stimulation of the globus pallidus in primary generalized dystonia. N Engl J Med 2005;352:459-467.

[177] Vidailhet M, Vercueil L, Houeto JL, et al. Bilateral, pallidal, deep-brain stimulation in primary generalised dystonia: a prospective 3 year follow-up study. Lancet Neurol 2007;6:223-229. 
[178] Quartarone A, Classen J, Morgante F, Rosenkranz K, Hallett M. Consensus paper: use of transcranial magnetic stimulation to probe motor cortex plasticity in dystonia and levodopa-induced dyskinesia. Brain Stimul 2009;2:108-117.

[179] Quartarone A, Rizzo V, Bagnato S, et al. Homeostatic-like plasticity of the primary motor hand area is impaired in focal hand dystonia. Brain 2005;128:1943-1950.

[180] Stefan K, Kunesch E, Cohen LG, Benecke R, Classen J. Induction of plasticity in the human motor cortex by paired associative stimulation. Brain 2000;123 Pt 3:572-584.

[181] Quartarone A, Siebner HR, Rothwell JC. Task-specific hand dystonia: can too much plasticity be bad for you? Trends Neurosci 2006;29:192-199.

[182] Tamura Y, Ueki Y, Lin P, et al. Disordered plasticity in the primary somatosensory cortex in focal hand dystonia. Brain 2009;132:749-755.

[183] Weise D, Schramm A, Beck M, Reiners K, Classen J. Loss of topographic specificity of LTD-like plasticity is a trait marker in focal dystonia. Neurobiol Dis 2011;42:171176.

[184] Weise D, Schramm A, Stefan K, et al. The two sides of associative plasticity in writer's cramp. Brain 2006;129:2709-2721.

[185] Edwards MJ, Huang YZ, Mir P, Rothwell JC, Bhatia KP. Abnormalities in motor cortical plasticity differentiate manifesting and nonmanifesting DYT1 carriers. Mov Disord 2006;21:2181-2186.

[186] Magarinos-Ascone CM, Figueiras-Mendez R, Riva-Meana C, Cordoba-Fernandez A. Subthalamic neuron activity related to tremor and movement in Parkinson's disease. Eur J Neurosci 2000;12:2597-2607.

[187] Magarinos-Ascone CM, Regidor I, Gomez-Galan M, Cabanes-Martinez L, FigueirasMendez R. Deep brain stimulation in the globus pallidus to treat dystonia: electrophysiological characteristics and 2 years' follow-up in 10 patients. Neuroscience 2008;152:558-571.

[188] Bhatia KP, Marsden CD. The behavioural and motor consequences of focal lesions of the basal ganglia in man. Brain 1994;117 ( Pt 4):859-876.

[189] Mink JW. The basal ganglia: focused selection and inhibition of competing motor programs. Prog Neurobiol 1996;50:381-425.

[190] Bonsi P, Martella G, Cuomo D, et al. Loss of muscarinic autoreceptor function impairs long-term depression but not long-term potentiation in the striatum. J Neurosci 2008;28:6258-6263.

[191] Martella G, Tassone A, Sciamanna G, et al. Impairment of bidirectional synaptic plasticity in the striatum of a mouse model of DYT1 dystonia: role of endogenous acetylcholine. Brain 2009;132:2336-2349.

[192] Gernert M, Hamann M, Bennay M, Loscher W, Richter A. Deficit of striatal parvalbumin-reactive GABAergic interneurons and decreased basal ganglia output in a genetic rodent model of idiopathic paroxysmal dystonia. J Neurosci 2000;20:7052-7058.

[193] Pisani A. Towards a new era for dystonia, a high priority for biomedical research. Neurobiol Dis 2011;42:125-126. 


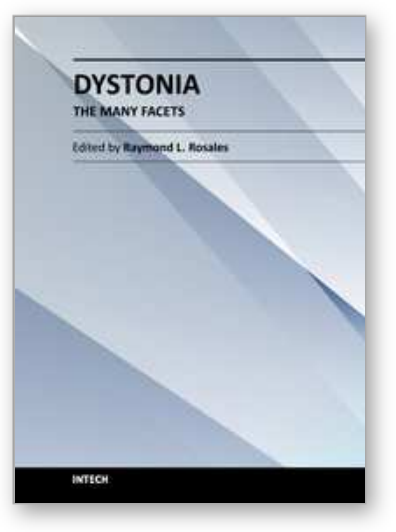

\author{
Dystonia - The Many Facets \\ Edited by Prof. Raymond Rosales
}

ISBN 978-953-51-0329-5

Hard cover, 220 pages

Publisher InTech

Published online 14, March, 2012

Published in print edition March, 2012

Dystonia has many facets, and among those, this book commences with the increasingly associated genes identified, including a construct on how biology interacts with the dystonia genesis. The clinical phenomenology of dystonia as approached in the book is interesting because, not only were the cervical, oromandibular/lingual/laryngeal, task-specific and secondary dystonias dealt with individually, but that the associated features such as parkinsonism, tremors and spasticity were also separately presented. Advances in dystonia management followed, and they ranged from dopaminergic therapy, chemodenervation, surgical approaches and rehabilitation, effectively complementing the approach in dystonia at the clinics. A timely critical pathophysiologic review, including the muscle spindle involvement in dystonia, is highlighted at the book's end.

\title{
How to reference
}

In order to correctly reference this scholarly work, feel free to copy and paste the following:

Pierre Burbaud (2012). Dystonia Pathophysiology: A Critical Review, Dystonia - The Many Facets, Prof. Raymond Rosales (Ed.), ISBN: 978-953-51-0329-5, InTech, Available from: http://www.intechopen.com/books/dystonia-the-many-facets/dystonia-pathophysiology-a-critical-review

\section{INTECH}

open science | open minds

\section{InTech Europe}

University Campus STeP Ri Slavka Krautzeka 83/A 51000 Rijeka, Croatia Phone: +385 (51) 770447 Fax: +385 (51) 686166 www.intechopen.com

\author{
InTech China \\ Unit 405, Office Block, Hotel Equatorial Shanghai \\ No.65, Yan An Road (West), Shanghai, 200040, China \\ 中国上海市延安西路65号上海国际贵都大饭店办公楼 405 单元 \\ Phone: +86-21-62489820 \\ Fax: +86-21-62489821
}


(C) 2012 The Author(s). Licensee IntechOpen. This is an open access article distributed under the terms of the Creative Commons Attribution 3.0 License, which permits unrestricted use, distribution, and reproduction in any medium, provided the original work is properly cited. 